\title{
Syringe punch and delivery protocol for well diffusion test
}

\begin{abstract}
Phytochemicals or agents showing anti-microbial activities are routinely tested for the search of new medicinal drugs which have efficient potential and treatment roles against various diseases. Routinely used well diffusion test relies on agar gel punching using a cork borer or biopsy punch, resulting in agar gel disturbance and tearing. The precise test agent/ substance delivery is also undesirable and is not precise in most cases. The present study describes a simple syringe based punch and delivery system that can be easily customized resulting in desirable well size. Due to its minimal price, it can be discarded after every use and is replaceable with easily available materials with no cost of production.
\end{abstract}

Volume 4 Issue I - 2018

Soumitra Nath

Department of Biotechnology, Gurucharan College, India

Correspondence: Soumitra Nath, Department of Biotechnology, Gurucharan College, Silchar, Assam, India,Tel +919401374737, Email nath.soumitral@gmail.com

Received: January 25, 2018 | Published: February 08, 2018

Keywords: anti-microbial, well diffusion, agar, syringe punch, delivery system

\section{Syringe punch system}

A proper and precise method of well preparation and test substance delivery remains a major concern in phytochemical and microbial research. Currently used laboratory methods deals with disc diffusion ${ }^{1}$ and well diffusion, ${ }^{2,3}$ but both serve their valuable purpose for a particular test type. The process of well preparation and test substance delivery varies from laboratory to laboratory, and most of the researchers opts their lab-based method of well preparation. Routinely used cork borer, micropipette and biopsy punch is being used for gel punching ${ }^{4}$ but practically face some difficulties in handling and may damage the well walls of the agar gel while punching and sucking (blowing-up). A modified system of well preparation, termed as Syringe Puncher is designed (Figure 1) with easily available materials with no cost of production and easily replaceable. The syringe puncher system consists of a syringe (for sucking), a sharp metal tube (for punching and sucking the gels) and a rubber/plastic tube (for connecting syringe and metal tube).

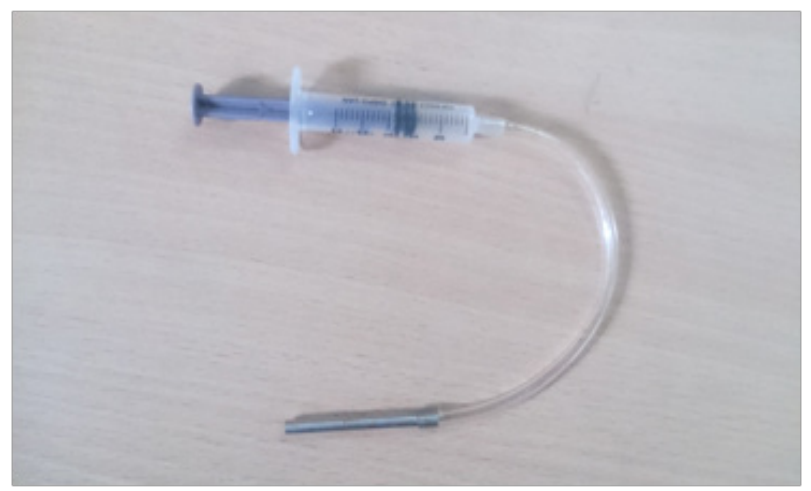

Figure I Syringe puncher.

\section{Syringe}

All the three basic part of a syringe performs a specialized role in punching and blowing-up of gels. The piston-type rod with a slightly cone-shaped top known as plunger passes inside the barrel and creates an excellent vacuum environment for proper, quick and easy blowing-up of desired gels. The other end of the barrel is a tube that is open at one end and tapers into a hollow tip/hub which provides an attachment for the rubber tube.

\section{Rubber/plastic tube}

Flexible rubber/plastic tube connect the syringe and metal tube and provide a considerable ease in handling and precise punching.

\section{Metal tube}

The working instrumental end is a metal tube which is a sharp, hollow tube of $6 \mathrm{~mm}$ in diameter. Metal tube of different sizes may also be connected for customized well preparation. Thus, the application of syringe puncher may provide an efficient and precise well preparation in the antimicrobial assay. The problems with agar gel disturbance and tearing in existing protocol can be minimized. Syringe puncher can also be easily customized resulting in desirable well size.

\section{Syringe delivery system}

Antimicrobial assay requires precise delivery of test extract/ substance in a defined volume at a specific well. Currently, used delivery methods include a micropipette or a dropper, and are good enough for the release of test extract/ substance into the well. Sometimes, the non-volatile substance or dense plant extract forms a clog in the micro-tip. ${ }^{5}$ To overcome the problem, the tips are either cut to widen the release surface or a gentle pressure-press is applied on the micropipette. However, in both the cases, the substances delivered are undesirable and not precise; they may also overflow in the well and spread in agar gels. ${ }^{6}$ Most of the antibacterial assay require proper disposal of test materials, immediately after use. Micro-tips or droppers are at high risk of microbial contamination, which is often disposed of. The routinely used micropipettes are too costly to discard, so they are sterilized after every single use. The problem lies on total decontamination of micropipette after being used for a long time.

This modification of routine protocol is the application of the syringe delivery method (Figure 2), where a micro-tip is connected to the syringe hub (tip). The rubber headed plunger fitted inside the barrel eases the release of the test substance. The other end of the syringe holds the micro-tip and helps in the slow but controlled release of the test material. The major advantage is its effortless assembly and cheap availability. Due to its minimal price, it can be discarded after every use and is replaceable with easily available materials with no cost of production. Non-volatile substances and plant extract consisting of oily compounds can also be placed in the well in considerable amount. 
However, replacing the micro-tip with fine needle assemblage may advance the nano-scale delivery of substances/plant extracts.

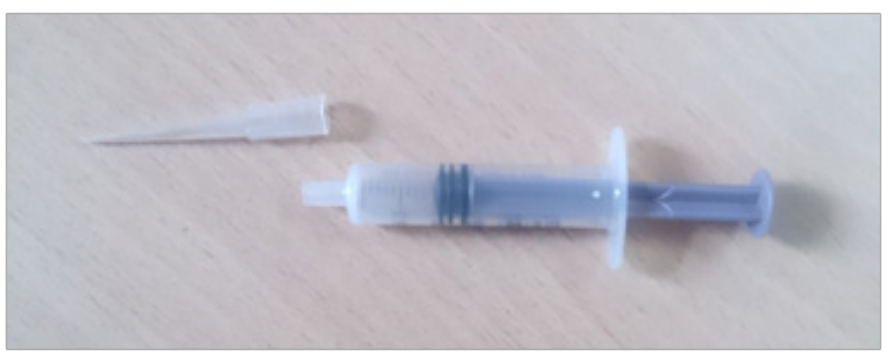

Figure 2 Syringe based agent delivery system.

\section{Method summary}

A modified system of well preparation and test agent/substance delivery, termed as Syringe puncher and delivery system is designed through easily available resources with no cost of production and easily replaceable. Non-volatile substances and plant extract consisting of oily compounds can also be placed precisely in the well in considerable amount.

\section{Acknowledgements}

Author extends his grateful thanks to the Department of Biotechnology (DBT), Govt. of India, New Delhi, for the establishment of and facilitating research at Institutional Biotech Hub and Bioinformatics Centre in Gurucharan College, Silchar, India.

\section{Conflict of interest}

The author declares no conflict of interest.

\section{References}

1. Jorgensen JH, Turnidge JD. Susceptibility test methods: dilution and disk diffusion methods. In Manual of Clinical Microbiology. USA; 2015. p. 1253-1273.

2. Bassolé IHN, Juliani HR. Essential oils in combination and their antimicrobial properties. Molecules. 2012;17(4):3989-4006.

3. Magaldi S, Mata-Essayag S, De Capriles CH, et al. Well diffusion for antifungal susceptibility testing. Int J Infect Dis. 2004;8(1):39-45.

4. Dash M, Patra JK, Panda PP. Phytochemical and antimicrobial screening of extracts of Aquilaria agallocha Roxb. African Journal of Biotechnology. 2008;7(20):3531-3534.

5. Valgas C, Souza SMD, Smânia EF, et al. Screening methods to determine antibacterial activity of natural products. Brazilian Journal of Microbiology. 2007;38(2); 369-380.

6. Dijkstra J, De Jager CP. Gel Double-Diffusion Test in Plates. In Practical Plant Virology. 1998:341-347. 